\section{The health and economic impact of dengue in Latin America}

\author{
El impacto sanitario y económico del dengue en \\ Latinoamérica
}

\author{
${ }^{1}$ Facultad de Medicina, \\ Universidad Central \\ de Venezuela, Caracas, \\ Venezuela. \\ Correspondence \\ J. R. Torres \\ Instituto de Medicina \\ Tropical, Facultad de \\ Medicina, Universidad \\ Central de Venezuela. \\ Apartado 47623, Caracas \\ 1041-A, Venezuela. \\ torresj@iname.com
}

\begin{abstract}
In the last two decades, all countries in the tropical regions of Latin America have experienced marked increases in the incidence of both classic dengue and dengue hemorrhagic fever. Major risk factors for the occurrence of dengue in the region, as well as some regional peculiarities in its clinical expression, such as the extensive involvement of older age groups, have been defined. While little information exists on the economic impact of dengue in the region in terms of disease burden, the estimated loss associated with the disease is on the same order of magnitude as tuberculosis, sexually transmitted diseases (excluding HIVIAIDS), Chagas disease, leishmaniasis, or intestinal helminths. Therefore, similar priority should be given in the allocation of resources for dengue research and control. Data on cost-efficacy and cost-benefit analysis of dengue control programs in Latin America are scarce; however, the cost per DALY averted by control programs during endemic periods appears low, as compared to other mosquito-borne diseases like yellow fever, leishmaniasis, or malaria. Additionally, the cost-benefit ratio of the control programs has proven to be positive.
\end{abstract}

Dengue; Risk Factors; Health Care Costs
Jaime R. Torres 1

Julio Castro 1

\section{Background}

Dengue virus infection is without doubt the most common arthropod-borne disease worldwide, representing a major health and economic burden to many countries with already limited resources. During the last two decades, all countries in the tropical regions of Central and South America, as well as most of the Caribbean, have experienced a marked increase in the incidence of both classic dengue and, for the first time, dengue hemorrhagic fever (DHF).

The first large epidemic of DHF in the region occurred in Cuba in 1981, with 24,000 cases of DHF and 10,000 cases of dengue shock syndrome (DSS) and 158 deaths reported during a 3-month period 1,2,3,4. In 1986 and 1987 massive dengue outbreaks were reported in Brazil 5,6. In 1990 nearly one-fourth of the 300,000 inhabitants of Iquitos, Peru, acquired dengue fever 7 , and in the same year 3,108 cases of DHF with 78 deaths were reported in Venezuela 1 .

The last available regional figures, from the year 2005, indicate the occurrence of 427,627 cases of infection, 14,557 of which were DHF/ DSS, with 159 deaths ${ }^{8}$. Several Latin American countries report the concurrent circulation of all four viral serotypes (Table 1) 1 .

The widespread distribution and rising incidence of dengue virus infection is related to a wider distribution of Aedes aegypti due to lack of effective vector containment programs and the 
Table 1

Dengue cases reported in the Americas, according to country, form of the disease, and (when available) viral serotype isolated, 2005.

\begin{tabular}{|c|c|c|c|c|}
\hline Country & Dengue, all forms & Serotype & Dengue hemorrhagic fever & Deaths \\
\hline Argentina & 34 & DEN 2 & 0 & 0 \\
\hline Bolivia & 4,443 & DEN 2, 3 & 10 & 0 \\
\hline Brazil & 203,789 & DEN 1, 2, 3 & 433 & 43 \\
\hline Colombia & 30,475 & DEN $1,2,3$ & 4,306 & 47 \\
\hline Costa Rica & 37,798 & DEN 1 & 52 & 2 \\
\hline Cuba & 75 & DEN & - & - \\
\hline Dominican Republic & 2,860 & DEN & 84 & 18 \\
\hline Ecuador & 12,131 & DEN 1, 3 & 334 & 14 \\
\hline El Salvador & 15,290 & DEN 2, 4 & 207 & 0 \\
\hline Guatemala & 6,341 & DEN $1,2,3,4$ & 32 & 1 \\
\hline Honduras & 18,843 & DEN $1,2,4$ & 1,795 & 6 \\
\hline Mexico & 16,862 & DEN 1, 2, 3 & 4,255 & - \\
\hline Nicaragua & 1,735 & DEN 1, 2, 4 & 177 & 12 \\
\hline Panama & 4,000 & DEN 1,2 & 2 & 1 \\
\hline Paraguay & 405 & DEN 2 & 0 & 0 \\
\hline Peru & 6,358 & DEN $1,2,3,4$ & 16 & 0 \\
\hline Puerto Rico & 5,701 & DEN 2, 3, 4 & 19 & 7 \\
\hline Venezuela & 42,198 & DEN $1,2,3,4$ & 2,681 & 4 \\
\hline Barbados & 320 & DEN 1, 3 & - & - \\
\hline Belize & 380 & DEN 1, 2, 3 & 0 & 0 \\
\hline Bermuda & 2 & DEN & 0 & 0 \\
\hline Cayman Islands & 1 & DEN & 0 & 0 \\
\hline Curaçao & 265 & DEN & - & - \\
\hline Dominica & 11 & DEN & 4 & - \\
\hline French Guiana & 4,365 & DEN $1,2,3,4$ & 0 & 0 \\
\hline Guadaloupe & 3,364 & DEN 2, 3, 4 & 6 & 0 \\
\hline Guyana & 178 & DEN & 0 & 0 \\
\hline Jamaica & 46 & DEN & - & - \\
\hline Martinique & 6,083 & DEN 2, 3, 4 & 3 & 4 \\
\hline St. Lucia & 1 & DEN 4 & 0 & 0 \\
\hline St. Vincent \& Grenadines & 8 & DEN 3 & 0 & 0 \\
\hline Suriname & 2,853 & DEN 1, 2, 3 & 141 & - \\
\hline Trinidad \& Tobago & 411 & DEN 3 & 0 & 0 \\
\hline Turks \& Caicos Islands & 1 & DEN & - & - \\
\hline Total & 427,627 & - & 14,557 & 159 \\
\hline
\end{tabular}

Source: Reports to the Pan-American Health Organization by the Ministries of Health of the respective countries

(http://www.paho.org/common/Display.asp?Lang=E\&ReclD=8979).

increase in population density in many large urban areas, with the consequent deterioration of the urban environment 2,4. Furthermore, increased air travel and hence the spread of the mosquito vector and viremic patients almost certainly facilitates the spread of dengue fever. Nevertheless, the reason for the change in Latin America from simple dengue fever epidemics to a severe hemorrhagic disease, often associated with shock, or DHF/DSS, is not fully understood 2,4,9.
In the last decade, the spread of dengue fever was most dramatic in virtually all Latin American and Caribbean countries infested with Ae. aegyp$t i$. A sharp increase was observed in the number of cases reported each year, from over 250,000 in the early 1990s to more than 600,000 by the end of the century 2 . In the last 10 years, Brazil has accounted for $\approx 70 \%$ of reported dengue fever cases in the Americas. In that same country, DHF cases increased 45-fold from 2000 to 2002, compared to a 3.3-fold increase in dengue fever cases dur- 
ing the same period, and in 2002, the absolute number of deaths due to DHF $(\mathrm{N}=150)$ exceeded malaria deaths for the first time 10 .

Serological surveys suggest the occurrence of millions of dengue infections in the region 11 as illustrated in Brazil, where serologic investigations in 1994 estimated nearly 4 million cases of dengue fever, compared to the clinically estimated 1 million 6 .

From 1968 to 1980, only 60 cases of DHF (from 5 countries) were reported in the entire region. However, after its emergence in Cuba in 1981 12, epidemics or sporadic cases of DHF have been reported in at least 25 countries in the Americas 13 . Since 1989, with a large epidemic with 2,500 cases of DHF, Venezuela has reported large numbers of DHF cases every year, and in 1995 the country recorded the largest regional outbreak with almost 30,000 cases of classic dengue and 5,000 cases of DHF. Although dengue virus serotypes 1, 2, and 4 were isolated during this epidemic, DEN-2 was by far the predominant serotype 14 .

Remarkably, despite the large number of victims, there have been few estimates of dengue's economic or social impact. The lack of estimates on the impact of endemic dengue is important because such estimates are essential to help policymakers allocate resources for research, prevention, and control activities.

\section{Regional epidemiology}

Currently, dengue and occasionally DHF affect most of the American continent and several islands of the Caribbean. According to the Pan American Health Organization (PAHO), dengue transmission has increased significantly in the region in the last two decades (Figure 1). Incidence of the disease has shown cyclical peaks and troughs since 1980 1,13,15. The epidemic in Cuba produced the high peak in 1981 (with 344,203 cases in Cuba). The seven-fold reduction (to around 50,000 cases) in dengue incidence observed immediately after that year can be attributed to the rapid eradication of dengue in Cuba 15 .

Overall, between 1995 and 1997, the region experienced an annual increase in dengue fever incidence rate of $+12 \%$ and $+35 \%$, respectively, with a simultaneous increase in DHF incidence of $+61.87 \%$. Martinica, Trinidad \& Tobago, and Cuba experienced $a+100 \%$ annual increase in the DHF incidence rate, followed by Venezuela and Puerto Rico with $+73.33 \%$ and $+61.29 \%$, respectively 15,16 .

By the year 2002, 37 countries of Central and South America and the Caribbean reported dengue transmission, of which 21 reported cases of DHF and 14 reported fatal DHF cases. The most heavily affected sub-region was South America, and the hardest hit countries were Brazil, Co-

Figure 1

Incidence pattern of dengue hemorrhagic fever (DHF) in the Americas.

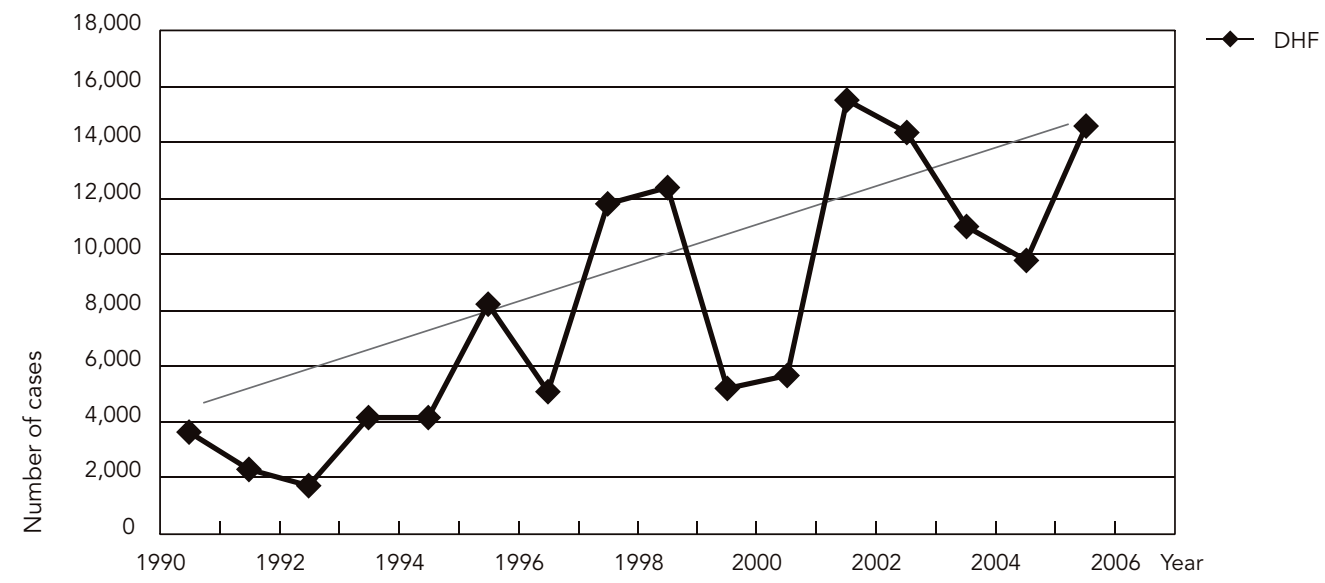


lombia, Honduras, and Venezuela 1,15. More worrisome and remarkable has been the trend observed in DHF incidence in the region during the last decade. After the onset of the epidemic in Cuba in 1981, DHF/DSS incidence remained at negligible levels for 7 years until rebounding suddenly in 1989, with the second largest DHF/DSS epidemic, this time in Venezuela. Since 1989, the number of reported DHF cases has been significant, with moderate yearly variations, except for an unusual increase in 1997 (11,645 cases). These variations and the lack of correspondence between the incidence of classic dengue and DHF (Figure 1) could be due to the intense active monitoring of DHF, as opposed to the passive monitoring normally used for classic dengue.

Importantly, every 3 to 4 years a reduction in dengue incidence is followed immediately by a 2 to 3 -year increase in reported cases. However, the new peaks in incidence have been consistently higher than those observed in the previous cycle. In the last decade, the maximum incidence peaks were observed in 1987 (134,390 cases), 1991 (157,340 cases), 1995 (284,476 cases), and 1997 (387,459 cases) with an evident upward trend 1,16. In 2002, dengue incidence leaped to $1,015,420$ cases, while DHF incidence remained basically unaltered 8 .

The 7 years of low DHF incidence from 1982 to 1988 could be related to the absence of virulent strains in the area, since the strain causing the Cuban epidemic in 1981 probably did not circulate in the other countries of the region after the epidemic subsided 14 . Recent evidence indicates that since 1989 at least 4 countries (Venezuela, Brazil, Mexico, and Colombia) have isolated viral strains of Southeast Asian origin, potentially associated with DHF epidemics 15 . In fact, around those years the incidence of DHF/DSS in the Americas began to increase steadily, until 2001 , with a high of 15,376 DHF/DSS cases out of 610,625 total dengue cases reported in the region. While these numbers are obviously affected by underreporting, they do indicate that dengue and DHF constitute an important public health problem in the Americas.

Since 2001 (Table 1), all 4 dengue serotypes have circulated regularly in the Americas, and at least 14 countries have reported the simultaneous presence of more than one serotype. Additionally, dengue virus 3 was recently reintroduced in the region after 17 years of complete absence 1 . During the years 2000 and 2001, six countries (Barbados, Dominican Republic, Ecuador, Panama, Peru and Venezuela) documented the simultaneous circulation of all 4 dengue serotypes. Therefore, the number of countries with more than one viral serotype circulating has steadily increased, thus favoring the occurrence of more cases of secondary infection and consequently an increase in the risk of DHF/DSS.

Factors such as lack of diagnostic facilities in some countries, delayed diagnosis, inefficient control programs, and deficient epidemiological and entomological surveillance systems may all play a role in increasing the magnitude of the problem in the area.

In general, relevant risk factors for the occurrence of dengue in a given region are included among the so-called macro-determinants 5,6,7,17, which in Latin America have been defined as:

a) Population growth: it has been estimated that by 2020 the urban population in Latin America will be some $80 \%$ (up from $42 \%$ in 1954), and that by 2030 close to $50 \%$ of the population will live in mega-cities ( $\geq 10$ million inhabitants) 8,16 .

The incorporation of more land for food production and the negative impact of haphazard deforestation, in combination with a trend towards global warming, often create the conditions for the emergence of vector-borne diseases like dengue.

b) Inadequate and unplanned urbanization: this factor is vitally important in Latin America due to constant migration from the countryside to the cities, nearly always accompanied by the lack or inappropriate availability of water for human consumption and inadequate disposal of liquid and solid wastes, poor housing conditions, and abundant vectors 8,16 .

c) Air travel: along with internal migration, the marked increase in air travel favors the movement of dengue virus between endemic areas and other areas free of the disease, due to people's arrival during the disease incubation period (the viremic period can be long, and the virus can be detected in blood from two days before initial symptoms until eight days after) and subsequent risk of infection of local mosquitoes and development of epidemics. This situation is exemplified by the recent reemergence of dengue fever on Easter Island in Chile 1.

d) Global warming: although climatic factors can have a potentially negative impact on the emergence or reemergence of diseases, increased dengue transmission in a given geographic area appears to be multifactorial, with public health deficiencies rather than climate playing a key role. This is clearly illustrated by the recent dengue transmission pattern along the U.S. - Mexican border 11. In 1995, the Mexican state of Tamaulipas reported 4,479 cases of dengue, 2,361 of which in Reynosa, a Mexican city adjacent to Hidalgo, Texas, where only 7 autochthonous cases were recorded. While the two cities have equal 
climatic and ecological conditions and their populations have basically similar origins, the living conditions and income are markedly different ${ }^{11}$. e) Poor sanitary conditions: the main factors directly or indirectly influencing the magnitude of dengue transmission appear to be low socioeconomic status and poor sanitary conditions. While the other ecological, geographic, or climatic factors already mentioned can also play a role, it is clear that underlying nearly all the factors favoring dengue emergence are the consequences of negative human activity and the social inequalities characteristic of the contemporary world 8,12 .

f) Deterioration of the public health infrastructure: also contributing to worsen an already bleak situation is the deterioration of most regional public health systems, thus also jeopardizing the efficiency of Ae. aegypti control programs, further aggravated by ineffective and obsolete sanitary legislation. In addition, due to economic constraints faced by most Latin American countries, health authorities have prioritized contingency activities to combat epidemics, to the detriment of preventive measures.

g) Introduction of new and more complex secondary vectors: a potential additional risk is the introduction in the region of Ae. albopictus, an efficient dengue vector in Southeast Asia, which can act as both an urban and rural vector. Unlike Ae. aegypti, Ae. albopictus is not obligatorily anthropophilic and sometimes displaces the former from its habitat. After being reported in 1985 in the United States, for the first time on the continent 18 this vector has also been detected in several Latin American countries (Mexico, Honduras, Guatemala, Nicaragua, Panama, Cuba, Dominican Republic, Trinidad \& Tobago, Brazil, and Bolivia). Nevertheless, thus far its presence has not been associated unequivocally with the increase in dengue transmission.

\section{Regional peculiarities in clinical expression of the disease}

In contrast with observations from Asian countries, where DHF is limited almost entirely to young children, in the Americas older age groups are widely involved 6,19,20,21,22,23,24,25,26,27. For example, during the Venezuelan outbreak in 1989, about one-third of deaths were in patients over 14 years of age, while in the 1997 Cuban outbreak all the deaths occurred in adults 20,28. Moreover, in Puerto Rico in 1990-91, the reported mean age of patients was 38 years 21, and during the 1981 Cuban outbreak, DHF/DSS was more frequent among female adults 20 . Approximately $50 \%$ of all dengue cases reported in Brazil occur in adults from 20 to 40 years of age. Incidence is consistently higher in adults, having reached a high of 432.7 per 100,000 inhabitants in the $30-49$-year age group in 200210.

Recent regional data indicate that elderly patients ( $>65$ ) are more likely to be hospitalized and die, and are less likely to present hemorrhage, regardless of the infecting serotype. The elderly are apparently more likely than children and younger adults to develop severe illness when infected with the dengue virus, in a pattern similar to that of infants 29 .

Many potential factors can influence the type and severity of disease in any dengue epidemic 21 . Host immune response appears to be a major factor. Sequential infection with different dengue viral serotypes in the presence of non-neutralizing antibodies has been strongly incriminated in the occurrence of DHF/DSS 20,21,22, and cases of DHF/DSS are seldom documented in patients with primary infection $23,24,25,26$.

Individual factors like age, gender, genetic background, and underlying diseases can also play a role 20,22,23,26.

While only scattered reports exist in the medical literature on the pathological and clinical implications of acute acalculous cholecystitis complicating adults with DHF $30,31,32$, about $10 \%$ of 112 Venezuelan adults with dengue that we recently studied developed acute acalculous cholecystitis, according to clinical and ultrasound criteria ${ }^{9}$.

Use of World Health Organization criteria to classify disease severity in some Latin American countries has identified numerous dengue patients with signs of shock (e.g. hypotension, narrow pulse pressure, poor capillary filling, clammy skin, cold extremities, and lethargy) in the absence of thrombocytopenia or hemoconcentration. This new clinical category has been termed "dengue with associated signs of shock" and represented $3 \%$ of 614 confirmed cases in Nicaragua. Dengue patients with signs of shock clearly contribute to the disease's economic burden, since they require hospitalization, and length-of-stay is equal to duration of DSS. This phenomenon and its impact on the disease burden associated with dengue demands further examination 33

The relatively common occurrence of dengue virus infection among adults in Latin America allows for the recognition of some complications of the disease that are observed more rarely in children. An example is our recent description of acute bilateral parotitis 34 . Moreover, clinical experience continues to accumulate on the impact of co-infection involving dengue virus and other endemic agents present in the area, like Paracoc- 
cidioides braziliensis, Histoplasma capsulatum, Leishmania spp., etc ${ }^{2}$.

As epidemics progress, some Latin American countries have recorded a significant steady increase in the proportion of total cases presenting as DHF or DHF/DSS, and in case-fatality rates for both dengue fever and DHF/DSS 9,35. Adults appear less likely than children to suffer from DSS 36.

Whereas DHF/DSS continues to occur in the Americas in a significant number of adults, it is not clear whether this relates to population genetic background, epidemiological events, or other unknown factors.

\section{Regional health impact}

By and large, dengue is emerging today because of intense changes in society, demographics, the environment, and technologies, all of which affect the vector and it hosts. Thus, surveillance systems for dengue/DHF must necessarily change with the evolving disease patterns.

Dependable estimates on the disease incidence are difficult to obtain in any region of the world, since passive surveillance systems, which rely on health care providers to voluntarily report cases, usually underestimate the true number of cases. They may also reflect variable reporting over time and in different geographic locations; thus, it may be difficult to distinguish real changes in disease rates from artefacts in the reporting system.

Since reliable information is crucial to measure the burden and impact of any disease, more accurate methods are needed to estimate the incidence of diseases. Recent regional data suggest gross underreporting of dengue cases 6,37. However, defining an appropriate set factor to multiply for the number of reported cases as a way to obtain a more reliable estimate of actual cases is complicated by an age-related factor affecting the number of symptomatic cases. Indeed, when locally derived data and expert opinion were recently used in Puerto Rico to estimate the actual number of symptomatic dengue cases, a conservative multiplication factor of 27 for all cases among age groups older than 15 years (and 36 for groups under 10 years) were calculated 37 .

When comparing dengue's impact to that of other diseases, it is important to consider that the impact of all types of dengue put together is significantly greater than the impact of DHF alone. Thus, using only cases of DHF as a measure to compare the impact of dengue will seriously underestimate the economic burden imposed by dengue.
Little information exists on the economic impact of dengue in the region in terms of disease burden. A recent World Bank-sponsored study on the global burden of disease estimated 750,000 disability-adjusted life years (DALYs) lost each year worldwide to DHF 38,39. There are no estimates for DALYs lost to classic dengue. We have estimated the number of DALYs per case lost to any form of the disease in Venezuela in endemic periods as 0.012 and 36.83 for non-lethal and lethal cases, respectively 40 .

Estimates of total direct and indirect costs from the 1977 epidemic in Puerto Rico range from US $\$ 6.1$ million to US\$15.6 million (approximately US\$26 to US\$31 per symptomatic case) 41 . The 1981 epidemic in Cuba, with a total of 344,203 reported cases, cost some US\$103 million (approximately US $\$ 299$ per reported case) 19 . The overall economic impact of the 1994 dengue epidemic in Nicaragua, which resulted in an estimated 60,916 cases of classic dengue and DHF, was calculated at US $\$ 2.7$ million (approximately US $\$ 44$ per case). Since the cost of hospitalizing dengue patients in Nicaragua is very high (US\$130 per day for a hospital bed), the disease clearly exacts a large economic burden. In fact, the cost of medical care accounted for $64 \%$ of the overall cost of that epidemic 42 .

Note that all the above estimates relate only to epidemics. There are few readily available dollar estimates on the economic impact of endemic dengue.

Based on the experience in Puerto Rico, using DALYs as a means of assessing dengue's economic impact, the disease was found to cause the loss of an average of 658 DALYs per year per million inhabitants 37 . It has been estimated that the loss to dengue is similar to the losses per million inhabitants in the Latin American and Caribbean region attributed to any of the following diseases or disease clusters: the childhood cluster (polio, measles, pertussis, diphtheria, tetanus), meningitis, hepatitis, or malaria. The loss is also of the same order of magnitude as any one of the following: tuberculosis, sexually transmitted diseases (excluding HIV/AIDS), tropical cluster (e.g., Chagas disease, leishmaniasis), or intestinal helminths 37 . These results suggest that when resources for research and control are allocated regionally, dengue should be given a priority equal to many other infectious diseases that are generally considered more important.

When comparing the impact of dengue versus other diseases in terms of DALYs, the majority of its impact is clearly borne by patients with classic dengue fever lasting approximately five days 37 . Since most families in the region have a relatively low income ( $\leq$ US $\$ 10,000$ /year), it is logical to as- 
sume that the largest share of the dengue burden is borne by those in the lower socioeconomic strata. Such people can ill afford the five or more days of productivity lost from dengue.

The current situation of dengue fever and DHF in the region remains alarming, and since there is no real short-term possibility of resolving most of the conditioning factors, prospects for control of the disease appear bleak. Since the availability of an effective vaccine against dengue is still remote, the only practical alternative to control the disease at present involves costly programs aimed at reducing the presence, and if possible, eradicating the vector from heavily infested urban areas 11,15,43.

In fact, in the 1950s and 1960s PAHO led an initially successful continental campaign aimed at averting the risk of urban yellow fever by eradicating Ae.aegypti. Unfortunately, less than twenty years later, distribution of the vector in the region was basically similar to that observed before the campaign 2,11,15.

Vector control methods, including source reduction, chemical larvicides and adulticides, and biological control agents are hampered by limited program capacity, lack of well-defined indicators and program targets, and poor understanding of control measures' efficacy and costeffectiveness, particularly in terms of reducing transmission. Major future epidemiological and operational research challenges include a better understanding of virus transmission dynamics and identification of transmission thresholds.

Data on cost-efficacy and cost-benefit analysis of dengue control programs in Latin America are almost nonexistent. Our analysis of the cost per DALY averted by the Venezuelan program during endemic periods was comparatively low (US\$122) as compared to other mosquito-borne diseases such as yellow fever (US\$396), leishmaniasis (US\$1,893), or malaria (US\$1,915). Meanwhile, the cost-benefit ratio of the dengue control program was also positive (US $\$ 0.46$ invested per dollar saved) 40 .

A key factor in any control program requiring a strong social participation component is "behavior change". As in other parts of the word, dengue prevention and control programs in the Americas have traditionally relied on educational approaches, on the premise that knowledge would lead to behavior change 11,15. However, experience with this and similar programs, such as HIV and diarrheal disease prevention and control, have shown a poor correlation between improved knowledge and behavior change. Hence, emphasis must be shifted to the development of behavior change interventions. For this purpose, Ministries of Health and communities need to develop stronger links both among themselves and with other key partners in order to achieve a sustainable reduction in the risk of infection and burden of disease.

PAHO reported that in 1995, only about US\$104 million was spent on dengue control activities in the Americas 42. This amount is clearly insufficient for the purpose. Therefore, unless significantly greater resources are allocated and more aggressive and effective vector control measures are implemented, Latin American countries will continue to face repeated dengue epidemics and consequently an increased danger of DHF epidemics.

\section{Resumen}

En las últimas dos décadas, todos los países de las regiones tropicales de Latinoamérica han registrado un fuerte aumento en la incidencia de dengue clásica y dengue hemorrágica. Ya fueron identificados los principales factores de riesgo para la ocurrencia de dengue en la región, así como algunas peculiaridades regionales en su expresión clínica, como el comprometimiento frecuente de grupos de la tercera edad. Pese a la falta de información sobre el impacto económico del dengue en la región en términos de gastos por la enfermedad, las pérdidas estimadas asociadas con la misma son del mismo orden de magnitud que los de la tuberculosis, enfermedades sexualmente transmisibles (excluyendo VIH/SIDA), enfermedad de Chagas, leishmaniasis o parasitosis intestinales. Por tanto, la investigación y control del dengue merecen niveles de prioridad semejantes a las de otras enfermedades en términos de asignación de recursos. Los datos son escasos sobre los análisis de coste-eficacia y coste-beneficio de los programas de control del dengue en Latinoamérica; sin embargo, parece ser bajo el coste por AVAI evitado a través de programas de control durante períodos endémicos, en comparación con otras enfermedades transmitidas por mosquitos, como la fiebre amarilla, leishmaniasis o malaria. Asimismo, ya se comprobó la correlación positiva coste-beneficio de los programas de control.

Dengue; Factores de Riesgo; Costos de la Atención en Salud 


\section{Contributors}

Both authors were involved extensively in all aspects of the data analysis, conclusions, and drafting of the manuscript submitted for publication, in addition to the incorporation of the changes requested in the draft.

\section{References}

1. Schneider J, Droll D. A timeline for dengue in the Americas to December 31, 2000 and noted first occurrences. http://www.paho.org/English/HCP/ HCT/dengue_timeline.xls (accessed on Jun/2001).

2. Isturiz RE, Gubler DJ, Brea-del-Castillo J. Dengue and dengue hemorrhagic fever in Latin America and the Caribbean. Infect Dis Clin North Am 2000; 14:121-40.

3. Gubler DJ. Dengue and dengue hemorrhagic fever. Clin Microbiol Rev 1998; 11:480-96.

4. Guzman MG, Kouri GP, Bravo J, Soler M, Vasquez S, Santos M, et al. Dengue haemorrhagic fever in Cuba. II. Clinical investigations. Trans R Soc Trop Med Hyg 1984; 78:239-41.

5. Fiqueiredo LTM, Cavalcante SMB, Simões MC. Dengue serologic survey of school children in Rio de Janeiro, Brazil in 1986 and 1987. Bull Pan Am Health Organ 1990; 24:217-25.

6. Zagne SMO, Alves VGF, Nogueira RMR, Miagostovich MP, Lampe E, Tavares W. Dengue haemorrhagic fever in the state of Rio de Janeiro, Brazil: a study of 56 confirmed cases. Trans R Soc Trop Med Hyg 1994; 88:677-9

7. Herrera-Basto E, Prevots DR, Zarate ML, Silva JL, Sepulveda-Amor J. First reported outbreak of classical dengue fever at 1,700 meters above sea level in Guerrero State, Mexico, June, 1988. Am J Trop Med Hyg 1992; 46:649-53.

8. Pan American Health Organization. 2005: number of reported cases of dengue and dengue hemorrhagic fever (DHF), region of the Americas (by country and subregion). http://www.paho.org/ English/AD/DPC/CD/dengue-cases-2005.htm (accessed on Aug/2006).

9. Torres JR, Torres CG. Dengue in Latin America - a unique situation. Dengue Bull 2002; 26:62-9.

10. Siqueira JB, Turchi CM, Coelho GE, Da Rocha AC, Hatch DL. Dengue and dengue hemorrhagic fever, Brazil, 1981-2002. Emerg Infect Dis 2005; 11:48-53.
11. Pinheiro FP, Corber SJ. Global situation of dengue and dengue haemorrhagic fever, and its emergence in the Americas. World Health Stat Q 1997; 50:161-9.

12. Kouri G, Guzman MG, Bravo J. Hemorrhagic dengue in Cuba: history of an epidemic. Bull Pan Am Health Organ 1986; 20:24-30.

13. Gubler DJ, Trent DW. Emergence of epidemic dengue/dengue haemorrhagic fever as a public health problem in the Americas. Infect Agents Dis 1994; 2:383-5.

14. Salas RA, Tovar D, Barreto A, De Miller E, Leitmeyer $\mathrm{K}$, Rico-Hesse R. Serotypes and genotypes of dengue virus circulating in Venezuela, 1990-1997. Acta Cient Venez 1998; 49 Suppl 1:33-7.

15. Guzmán MG, Kouri G, Bravo JR. La emergencia de la fiebre hemorrágica del dengue en las Américas. Reemergencia del dengue. Rev Cubana Med Trop 1999; 51:5-13.

16. Kouri G, Guzmán MG, Valdés L, Carbonell I, Rosario D, Vázquez S, et al. Reemergence of dengue in Cuba: a 1997 epidemic in Santiago de Cuba. Emerg Infect Dis 1998, 4:89-92.

17. Colan E. Dengue epidemic Peru, 1990. MMWR Morb Mortal Wkly Rep 1991; 40:145-7.

18. Sprenger D, Wuithiranyagool $\mathrm{T}$. The discovery and distribution of Aedes albopictus in Harris County, Texas. J Am Mosq Control Assoc 1986; 2:217-9.

19. Kouri GP, Guzmán MG, Bravo J, Triana C. Dengue haemorrhagic fever/dengue shock syndrome: lessons from the Cuban epidemic, 1981. Bull World Health Organ 1989; 67:375-80.

20. Kouri G, Guzmán MG, Bravo J. Why dengue haemorrhagic fever in Cuba? 2. An integral analysis. Trans R Soc Trop Med Hyg 1987; 81:821-3.

21. Rigau-Perez JG. Puerto Rico Association of Epidemiologists: clinical manifestations of dengue hemorrhagic fever in Puerto Rico, 1990-1991. Rev Panam Salud Pública 1997; 1:381-8. 
22. Halstead SB. Pathogenesis of dengue: challenges to molecular biology. Science 1988; 239:476-81.

23. Gubler DJ. Dengue. In: Monath TP, editor. The arboviruses: epidemiology and ecology. v. II. Boca Raton: CRC Press Inc.; 1988. p. 223-60.

24. Pan American Health Organization. Dengue and dengue hemorrhagic fever in the Americas: guidelines for prevention and control. Washington DC: Pan American Health Organization; 1994. (Scientific Publication, 548).

25. Bravo JR, Guzmán MG, Kouri GP. Why dengue haemorrhagic fever in Cuba? 1. Individual risk factors for dengue haemorrhagic fever/dengue shock syndrome (DHF/DSS). Trans R Soc Trop Med Hyg 1987; 81:816-20.

26. Scott RM, Nimmannitya S, Bancroft WH, Mansuwan P. Shock syndrome in primary dengue infections. Am J Trop Med Hyg 1976; 25:866-74.

27. Sumarmo, Wulur H, Jahja E, Gubler DJ, Suharyono W, Sorensen K. Clinical observations on virologically confirmed fatal dengue infections in Jakarta, Indonesia. Bull World Health Organ 1983; 61:693701.

28. Guzmán MG, Deubel V, Pelegrino JL, Rosario D, Marrero M, Sariol C, et al. Partial nucleotide and amino acid sequences of the envelope and the envelope/nonstructural protein-1 gene junction of four dengue 2 virus strains isolated during the 1981 Cuban epidemic. Am J Trop Med Hyg 1995; 52:241-6.

29. García-Rivera EJ, Rigau-Pérez JG. Dengue severity in the elderly in Puerto Rico. Rev Panam Salud Pública 2003; 13:362-8.

30. Setiawan MW, Samsi TK, Wulur H, Surgianto D, Pool TN. Dengue haemorrhagic fever: ultrasound as an aid to predict the severity of the disease. Pediatr Radiol 1998; 28:1-4.

31. Sood A, Midha V, Sood N, Kaushal V. Acalculous cholecystitis as an atypical presentation of dengue fever. Am J Gastroenterol 2000; 95:3316-7.

32. Coton T, Debonne JM, Molinier S, Chaudier B, Gras C, Carre D, et al. Alithiasic cholecystitis and hemorrhagic dengue. Gastroenterol Clin Biol 1999; 23:789-90.
33. Harris E, Videa E, Perez L, Sandoval E, Tellez Y, Perez MA, et al. Clinical, epidemiologic, and virologic features of dengue in the 1998 epidemic in Nicaragua. Am J Trop Med Hyg 2000; 63:5-11.

34. Torres JR, Liprandi F, Goncalvez AP. Acute parotitis due to dengue virus. Clin Infect Dis 2000; 31: e28-9.

35. Guzmán MG, Kouri G, Halstead SB. Do escape mutants explain rapid increases in dengue casefatality rates within epidemics? Lancet 2000; 355: 1902-3.

36. Ibrahim NM, Cheong I. Adult dengue haemorrhagic fever at Kuala Lumpur Hospital: retrospective study of 102 cases. Br J Clin Pract 1995; 49: 189-91.

37. Meltzer MI, Rigau-Perez JG, Clark GG, Reiter P, Gubler DJ. Using disability-adjusted life years to assess the economic impact of dengue in Puerto Rico: 1984-1994. Am J Trop Med Hyg 1998; 59: 265-71.

38. Murray CJL, Lopez AD, editors. The global burden of disease: global burden of disease and injury series. v. I. Boston: Harvard School of Public Health; 1996.

39. Murray CJL, Lopez AD, editors. Global health statistics: global burden of disease and injury series. v. II. Boston: Harvard School of Public Health; 1996.

40. Laboratorio de Ciencias Sociales. Evaluación de impacto del proyecto control de enfermedades endémicas en función de costo-efectividad y costobeneficio. Informe final. Caracas: Laboratorio de Ciencias Sociales; 2000.

41. von Allmen SD, Lopez-Correa RH, Woodall JP, Morens DM, Chiriboga J, Casta-Velez A. Epidemic dengue fever in Puerto Rico, 1977: a cost analysis. Am J Trop Med Hyg 1979; 28:1040-4.

42. Ferrando JE. Estimate of the costs of the dengue epidemic in 1994 in Nicaragua. Washington DC: Pan American Health Organization; 1995. (Consultancy Report, 95.64).

43. Anonymous. The feasibility of eradicating Aedes aegypti in the Americas. Rev Panam Salud Pública 1997; 1:68-72.

Submitted on 09/Nov/2005

Final version resubmitted on 24/Aug/2006

Approved on 27/Sep/2006 